\title{
Transcatheter Aortic Valve Replacement for Inoperable Severe Rheumatic Aortic Stenosis with Prior Mitral Valve Prosthesis
}

\author{
Imad A. Alhaddad, MD, FACC, FACP \\ The Cardiovascular Center, Jordan Hospital, Amman, Jordan
}

\begin{abstract}
Transcatheter aortic valve replacement (TAVR) is traditionally indicated for calcific aortic stenosis. Rheumatic aortic valve disease is treated surgically due to the younger age of patients and a lack of significant calcification that can anchor transcatheter valves. However, severe comorbidities may increase surgical risk, necessitating less invasive therapeutic modalities. Here, we present the first case report of severe rheumatic aortic stenosis with prior mechanical mitral valve prosthesis and liver cirrhosis that was successfully treated by TAVR.
\end{abstract}

Copyright @ 2017 Science International Corp.

\section{Key Words:}

Aortic stenosis • Rheumatic valve disease • Mitral valve prosthesis • Transcatheter aortic valve replacement

\section{Introduction}

Transcatheter aortic valve replacement (TAVR) has become the procedure of choice for treating inoperable and high surgical risk patients with calcific degenerative severe symptomatic aortic stenosis $[1,2,3,4$, $5,6]$. However, the utilization of TAVR for severe aortic stenosis caused by rheumatic valve disease is uncertain due to the lack of significant calcification necessary to anchor transcatheter valves. Here, we report a case of severe rheumatic aortic stenosis with prior mechanical mitral valve prosthesis and high surgical risk related to liver cirrhosis that was treated successfully with TAVR.

\section{Case Presentation}

A 62-year-old woman with rheumatic heart disease and chronic atrial fibrillation underwent mitral valve replacement using a mechanical valve prosthesis in 1991. The surgery was complicated by hepatitis $C$ resulting from the recent development of liver cirrhosis. The patient presented with progressive dyspnea, orthopnea, and severe fluid overload consistent with class IV congestive heart failure. Diagnostic evaluation revealed severe aortic stenosis and tricuspid valve regurgitation, and she was referred for surgical aortic valve replacement and tricuspid valve repair. Hepatology evaluation suggested very high surgical risk due to chronic liver disease. Thus, she was referred for TAVR in the face of high surgical risk $[7,8]$.

Echocardiography revealed a D-shape septum with a left ventricular ejection fraction of $50 \%$, dilated left atrium and huge right atrium, and mildly dilated right ventricle with hypertrophy and normal systolic function. The aortic valve was fibrotic without significant calcification (consistent with rheumatic disease) with severe aortic stenosis and mild to moderate aortic regurgitation (annulus $20 \mathrm{~mm}$, peak gradient $65 \mathrm{mmHg}$, mean gradient $42 \mathrm{mmHg}$, and calculated aortic valve area $=0.8 \mathrm{~cm}^{2}$ ). The mechanical mitral valve prosthesis was functioning well, and the tricuspid valve exhibited

* Corresponding Author:

Imad A. Alhaddad, MD, FACC, FACP

The Cardiovascular Center

Jordan Hospital

Queen Nour Street, Amman, Jordan

Tel.: +962 656 26197; Fax: +962 656 26198; E-Mail: alhaddad63@gmail.com 
A

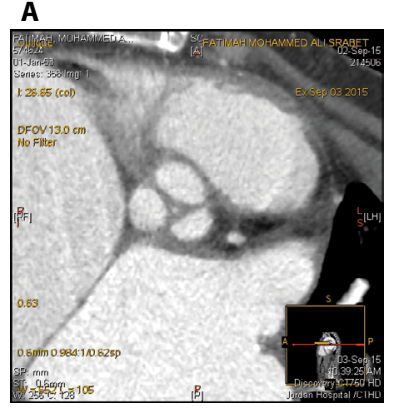

B

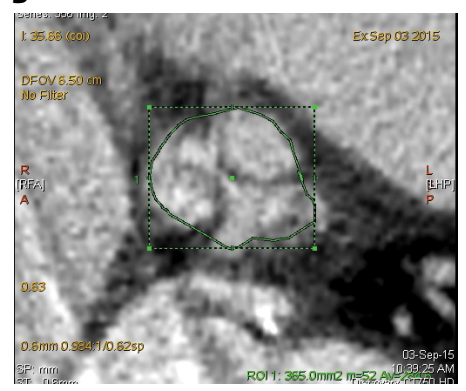

c

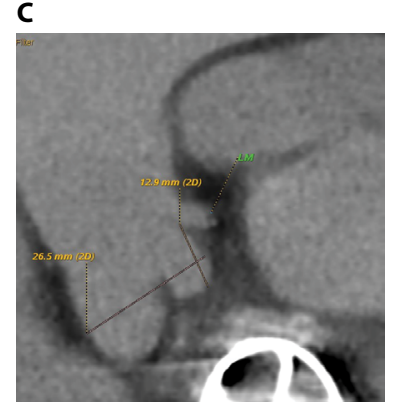

D

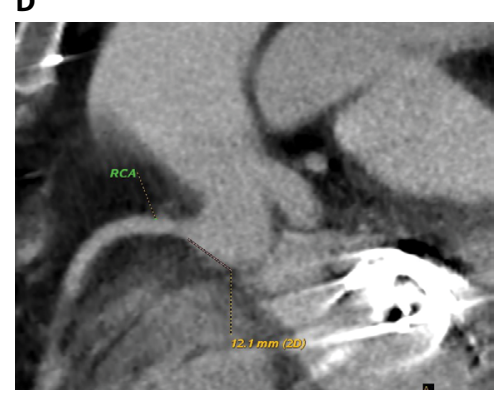

Figure 1. Cardiac computerized tomographic angiography showed a fibrotic aortic valve without significant calcifications (Panel A), annular area (Panel B), coronary sinus diameter and left main coronary height (Panel C), and right coronary height and the distance between the aortic annulus and mitral prosthetic valve $=10 \mathrm{~mm}$ (Panel D).

severe regurgitation with calculated pulmonary artery systolic pressure of $100 \mathrm{mmHg}$. Severe pulmonary hypertension appeared to be related to both prior mitral valve disorder and a recent development of congestive heart failure related to severe aortic stenosis.

Computerized tomographic angiography (CTA) showed the following: fibrotic aortic valve without significant calcification (Figure $1 \mathrm{~A}$ ), annular area $=365 \mathrm{~mm}^{2}$ (Figure 1B), coronary sinus diameter $=26.5 \mathrm{~mm}$ and left main coronary height $=12.9$ $\mathrm{mm}$ (Figure 1C), right coronary height $=12.1 \mathrm{~mm}$, and distance between the aortic annulus and mitral prosthetic valve $=10 \mathrm{~mm}$ (Figure 1D).

The procedure was performed in the catheterization laboratory under general anesthesia and transesophageal echocardiography (TEE) guidance. Percutaneous access was performed through the left common femoral artery with two ProGlide closure devices (Abbott Vascular Inc., Redwood City, California) pre-deployed to achieve homeostasis. Aortic valvuloplasty was performed using a 20$\mathrm{mm}$ diameter balloon during rapid pacing, which showed full expansion and stability without displacement related to prior mitral valve prosthesis. Next, a 23-mm valve (Edwards Sapien XT, Edwards Lifesciences, Irvine, California) was introduced through the e-sheath and positioned across the aortic valve (Video 1). The valve was implanted using the rapid pacing technique and balloon inflation (Video 2). Post-procedural angiography revealed a well-positioned prosthesis without significant aortic regurgitation (Video 3), and TEE revealed a wellfunctioning aortic valve. A $23-\mathrm{mm}$ valve provided $14 \%$ annular area oversizing, which was adequate to anchor and stabilize the valve in the absence of significant calcification. The patient was ambulated six hours after the procedure and discharged from the hospital three days later. At follow-up evaluation two weeks later, the patient showed a lack of symptoms, a well-functioning aortic valve, and improved pulmonary hypertension to $70 \mathrm{mmHg}$. The patient remained asymptomatic and stable 15 months after the procedure.

\section{Discussion}

To our knowledge, this is the first reported case of TAVR for rheumatic aortic stenosis with prior mechanical mitral valve prosthesis. This case has many unique features. In particular, rheumatic aortic valve disease usually lacks significant calcifications that are necessary to anchor the implanted valve and prevent its embolization. Also, the presence of prior mechanical mitral valve prosthesis could potentially complicate TAVR implantation by causing displacement, malposition, or even embolization. There are several usual recommendations for implanting a balloon-expandable transcatheter heart valve in patients with prior mitral valve prosthesis. First, the valve should be positioned more ventricularly due to anticipated aortic shift during deployment to prevent embolization. Second, stepwise and slow inflation of the valve is advised for proper and controlled implantation. Third, the implantation should be guided by aortography and TEE to evaluate interaction with the mitral prosthesis. We also believe that balloon valvuloplasty is mandatory in such cases prior to valve implantation for 


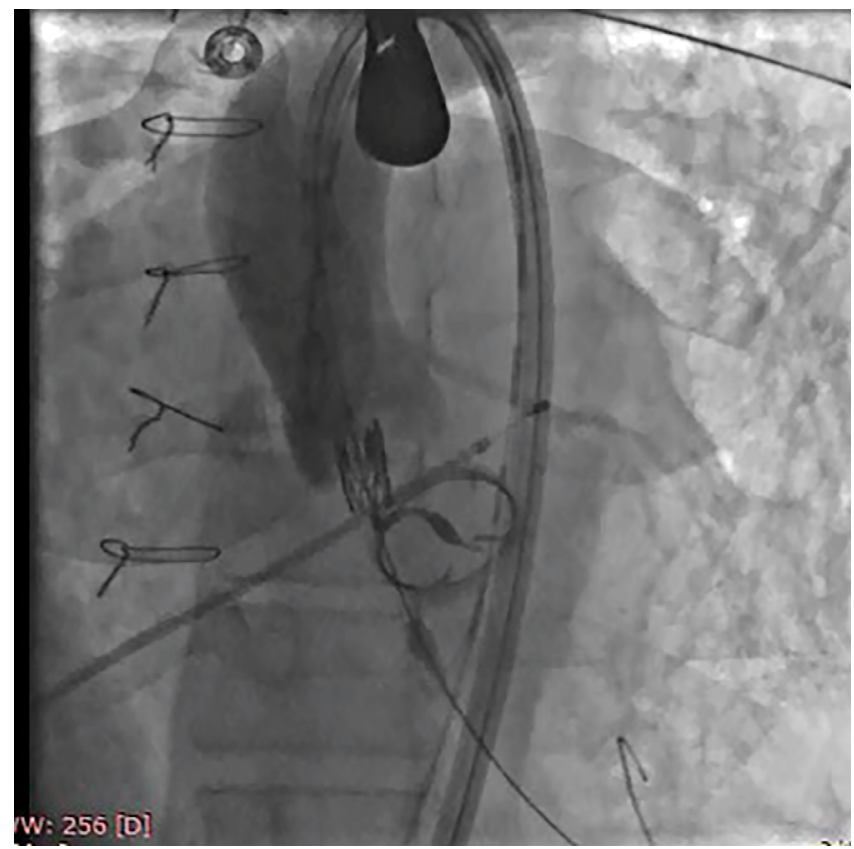

Video 1. Valve positioning prior to implantation. View supplemental video at https://doi.org/10.12945/j.jshd.2017.015.16. vid.01.

the following reasons. First, an inflated balloon can confirm full expansion of the fibrotic aortic valve leaflets. Second, balloon stability during inflation can indicate good anchoring, suggesting that the implanted valve is less likely to embolize. Third, it can allow examination of the interaction between the aortic valve and mitral prosthesis that could potentially cause displacement or malposition.

Rheumatic valve disease usually inflicts younger patients, and surgical valve replacement is the procedure of choice for these patients. However, the presence of comorbidities (i.e., liver cirrhosis) and prior mitral valve prosthesis makes TAVR a potentially excellent solution for severe aortic stenosis.

Review of the literature revealed several case reports of TAVR in rheumatic heart disease. Bilge et al. described two patients with rheumatic aortic stenosis and high surgical risk who ultimately underwent TAVR [9]. Akujuo et al. presented a case in which TAVR was combined with transcatheter mitral valve implantation in a patient with both aortic and mitral valves affected by rheumatic valve stenosis [10]. Chainani et al. reported a case of left main percutaneous coronary intervention and TAVR in a patient with rheumatic heart disease and porcelain aorta

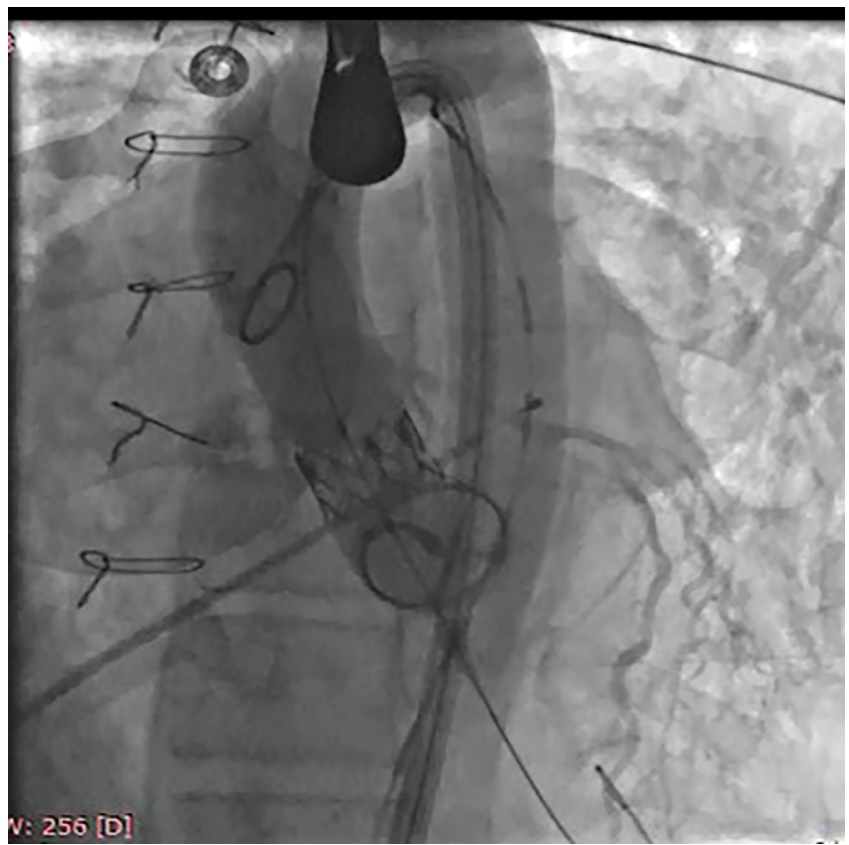

Video 2. Aortic valve implantation during rapid pacing. View supplemental video at https://doi.org/10.12945/j.jshd.2017.015.16. vid.02.

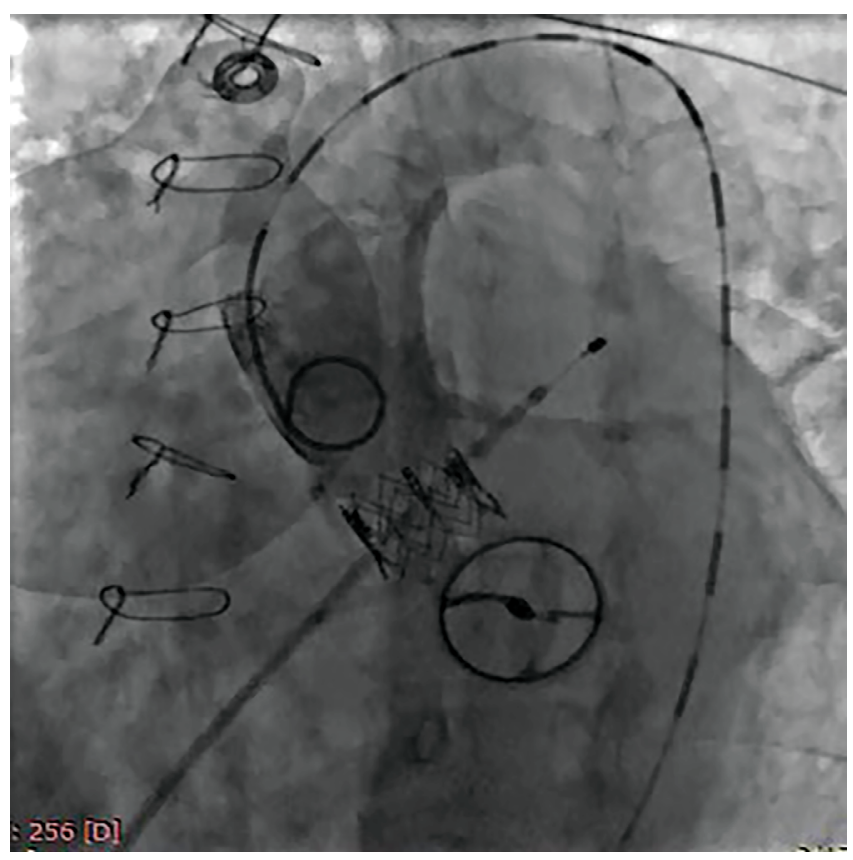

Video 3. Post trans-catheter aortic valve replacement angiography showing well-positioned valve without significant aortic regurgitation. View supplemental video at https://doi. org/10.12945/j.jshd.2017.015.16.vid.03. 
[11]. However, our case is unique because TAVR was performed in the presence of prior mitral valve prosthesis. On the other hand, several reports have been published on TAVR in the presence of prior mitral valve prosthesis $[12,13,14,15,16]$, although aortic stenosis in these reports was related to calcific aortic stenosis and not rheumatic disease as in our case. Thus, this is the first report of TAVR for rheumatic aortic stenosis with prior mitral valve prosthesis.

In conclusion, the indications for TAVR are evolving to include a wider range of patients and different valvular disorders. This is the first case demonstrating the feasibility of TAVR for rheumatic aortic stenosis with prior mitral valve prosthesis in the presence of high-risk features for surgical valve replacement. A registry of such patients with longer-term follow-up is necessary to establish the role of TAVR in rheumatic aortic stenosis.

\section{Conflict of Interest}

The authors have no conflict of interest relevant to this publication.

\section{Comment on this Article or Ask a Question}

\section{References}

1. Leon MB, Smith CR, Mack M, Miller DC, Moses JW, Svensson LG, et al. Transcatheter aortic-valve implantation for aortic stenosis in patients who cannot undergo surgery. N Engl J Med. 2010;363:1597-1607. DOI: 10.1056/NEJMoa1008232

2. Popma JJ, Adams DH, Reardon MJ, Yakubov SJ, Kleiman NS, Heimansohn D, et al. Transcatheter aortic valve replacement using a self-expanding bioprosthesis in patients with severe aortic stenosis at extreme risk for surgery. J Am Coll Cardiol. 2014;63:19721981. DOI: 10.1016/j.jacc.2014.02.556

3. Smith CR, Leon MB, Mack MJ, Miller DC, Moses JW, Svensson LG, et al. Transcatheter versus surgical aortic-valve replacement in high-risk patients. N Engl J Med. 2011;364:2187-2198. DOI: 10.1056/NEJMoa1103510

4. Adams DH, Popma JJ, Reardon MJ, Yakubov SJ, Coselli JS, Deeb GM, et al. Transcatheter aortic-valve replacement with a self-expanding prosthesis. N Engl J Med. 2014;370:1790-1798. DOI: 10.1056/NEJMc1408396

5. Vahanian A, Alfieri O, Andreotti F, Antunes MJ, Barón-Esquivias $\mathrm{G}$, Baumgartner $\mathrm{H}$, et al. Guidelines on the management of valvular hear disease (version 2012): The Joint Task Force on the Management of Valvular Heart Disease of the European Society of Cardiology (ESC) and the European Association for Cardio-Thoracic Surgery (EACTS). Eur Heart J. 2012;33:2451-2496. DOI: https://doi.org/10.1093/eurheartj/ ehs109

6. Nishimura RA, Otto $C M$, Bonow RO, Carabello BA, Erwin JP 3rd, Guyton RA, et al. 2014 AHA/ACC guideline for the management of patients with valvular heart disease: A report of the American College of Cardiology/American Heart Association Task Force on Practice Guidelines. J Am Coll Cardiol. 2014;63:e57-185. DOI: 10.1016/j.jacc.2014.02.536

7. Shah AM, Ogbara J, Herrmann HC, Fox Z, Kadakia M, Anwaruddin S, et al. Outcomes of transcatheter aortic valve replacement in patients with chronic liver disease. Catheter Cardiovasc Interv. 2015;86:888-894. DOI: $10.1002 / \mathrm{ccd} .25994$

8. Thakkar B, Patel A, Mohamad B, Patel NJ, Bhatt $P$, Bhimani $R$, et al. Transcatheter aortic valve replacement versus surgical aortic valve replacement in patients with cirrhosis. Catheter Cardiovasc Interv. 2016;87:955-962. DOI: 10.1002/ccd.26345

9. Bilge $M$, Saatci YA, Alemdar R, Ali S. Transcatheter aortic valve implantation with the CoreValve for the treatment of rheumatic aortic stenosis. Anadolu Kardiyolo Derg. 2014;14:296-297. DOI: 10.5152/ akd.2014.5226

10. Akujuo AC, Dellis SL, Britton LW, Bennett $\mathrm{EV}$, Jr. Transcatheter aortic and mitral valve implantation (TAMVI) in native rheumatic valves. J Card Surg. 2015;30:813-816. DOI: 10.1111/jocs. 12612

11. Chainani V, Perez $O$, Hanno R, Hourani $P$, Rengifo-Moreno $\mathrm{P}$, Martinez-Clark $\mathrm{P}$, et al. Left main percutaneous coronary intervention and transcatheter aortic valve replacement in a young male with rheumatic heart disease and porcelain aorta. Case Rep Cardiol. 2016; 2016:3671923. DOI: 10.1155/2016/3671923

12. Rodes-Cabau J, Dumont E, Miro S, Doyle $D$, De Larochelliere R, Clavel MA, et al. Apical aortic valve implantation in a patient with a mechanical valve prosthesis in mitral position. Circ Cardiovasc Interv. 2008;1:233. DOI: 10.1161/CIRCINTERVENTIONS.108.813592

13. Sari C, Bastug S, Ayhan H, Kasapkara HA, Durmaz T, Keles T, et al. Transfemoral aortic valve implantation in severe aortic stenosis patients with prior mitral valve prosthesis. Postepy Kardiol Interwencyjnej. 2015;11:304-311. DOI: 10.5114/ pwki.2015.55601

14. Garcia E, Albarran A, Heredia-Mantrana J, Guerrero-Pinedo F, RodriguezJ, Hernandez-Antolin R, et al. Transcatheter aortic valve implantation in patients with a mechanical mitral valve. Rev Esp Cardiol. 2011;64:10521055. DOI: 10.1016/j.recesp.2011.02.022

15. Manoharan G, Walton AS, Brecker SJ, Pasupati S, Blackman DJ, Qiao H, et al. Treatment of symptomatic severe aortic stenosis with a novel resheathable supraannular self-expanding transcatheter aortic valve system. JACC Cardiovasc Interv. 2015;8:1359-1367. DOI: 10.1016/j. jcin.2015.05.015

16. Soon JL, Ye J, Lichtenstein SV, Wood D, Webb JG, Cheung A. Transapical transcatheter aortic valve implantation in the presence of a mitral prosthesis. J Am Coll Cardiol. 2011;58:715-721. DOI: 10.1016/j. jacc.2011.04.023

Cite this article as: Alhaddad IA. TransCatheter Aortic Valve Replacement for Inoperable Severe Rheumatic Aortic Stenosis with Prior Mitral Valve Prosthesis. Structural Heart Disease. 2017;4(3):115-118. DOI: https://doi. org/10.12945/j.aorta.2015.015.16 